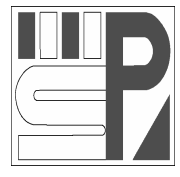

Science Press
Journal of Arid Land

2011, 3(4): 268-277

doi: $10.3724 /$ SP.J.1227.2011.00268

jal.xjegi.com; www.chinasciencejournal.com

\title{
Spatial heterogeneity of soil water content in the reversion process of desertification in arid areas
}

\author{
QuanLin MA ${ }^{1,2^{*}}$, Fang CHENG ${ }^{1}$, YouJun LIU ${ }^{1}$, FangLin Wang ${ }^{1}$, DeKuai ZHANG ${ }^{1}$, HuJia JIN $^{1}$ \\ ${ }^{1}$ Gansu Key Laboratory of Desertification Combating \& Minqin National Studies Station for Desert Steppe Ecosystem, Gansu \\ Desert Control Research Institute, Lanzhou 730070, China; \\ ${ }^{2}$ Institute of Desertification Studies, Chinese Academy of Forestry, Beijing 100091, China
}

\begin{abstract}
Sandy soils in arid, rain-fed environments have low and limited water content, which is a principal factor limiting vegetation development, and a key constraint controlling the structure and functions of the ecological systems in arid areas. The spatial heterogeneity of soil water content is a major soil property, and a focus of soil science and hydrology. On the southern edge of the Tengger Desert, sample plots were selected from mobile sand dunes in desertified lands that had been enclosed for 5,15 and 25 years, respectively. This study explored the dynamic and spatial heterogeneity of soil water content in these different layers of soil that were also in the reversion process of desertification. The results showed that the soil water content of the mobile sand dunes was highest when in the initial stages of the reversion process of desertification, while the soil water content in the $0-20 \mathrm{~cm}$, $20-40 \mathrm{~cm}$ and $40-60 \mathrm{~cm}$ layers of soil was $1.769 \%, 3.011 \%$, and $2.967 \%$ respectively, presenting a restoring tendency after 25 years of enclosure. There were significant differences, as a whole, in the soil water content among different restoration stages and different soil layers, respectively. Changes in soil water content, in different soil layers, at different restoration stages, exhibited exponential or spherical patterns. The spatial distribution of soil water content exhibited a mosaic patch pattern with obvious spatial heterogeneity. The ratio of the heterogeneity of spatial autocorrelation to gross spatial heterogeneity was greater than $50 \%$. The gross spatial heterogeneity of the 0-20 cm layer of soil improved gradually, while those of the $20-40 \mathrm{~cm}$ and $40-60 \mathrm{~cm}$ layers improved initially, then weakened in the reversion process of desertification. This study revealed that restoration with sand-binding vegetation reduced soil water content, and increased its spatial heterogeneity in arid areas. However, after 25 years of vegetation-soil system restoration, the soil water content started to increase and its spatial heterogeneity started to weaken. These results will further benefit the understanding of the ecological mechanism between soil water and sand-binding vegetation.
\end{abstract}

Keywords: Tengger Desert; reversion process of desertification; soil water content; sand-binding vegetation; geostatistical analysis

Soil water content, a primary source of ecosystem energy and material circulation, is the main factor affecting vegetation growth and development in arid and semiarid areas, determining ecosystem structure and function, and influencing ecosystem productivity (Berndtsson and Chen, 1994; Berndtsson et al., 1996). Spatial heterogeneity of soil water content, one of the major soil properties, is a hot topic in soil science and hydrology (Burgess and Webster, 1980; Rossi et al., 1991). Early studies on soil water content in China mainly used a traditional statistical method, which can only give an overview of the soil properties, and cannot reflect the changing features of their spatial patterns. With the application of the geostatistics method, studies on the spatial heterogeneity of soil water content have gradually increased, but few studies were reported in arid desert areas, and even fewer researhed the reversion process of desertification Zhao, 2002; Li et al., 2004; Pan and Wang, 2007). The study on soil water content and its spatial heterogeneity

Received 2011-05-09; accepted 2011-06-03

*Corresponding author: QuanLin MA (E-mail: mq1925@126.com) 
is not only a vital reference for understanding the relationship between vegetation and soil water content, such as the vegetation restoration process, the influence of soil water content on root growth, and the spatial patterns of desert plant species, it is also important in vegetation construction and management in arid desert areas (Fortin et al., 1989; Legender and Fortin, 1989). By substituting time with space, this study evaluated both the dynamic changes and spatial heterogeneity of soil water content at different restoration stages, and the changing processes and ecological function of soil water in the reversion process of desertification on the southern edge of the Tengger Desert. The aim is to provide a basic theory for restoration and management of sand-binding vegetation in arid areas.

\section{Study area}

The study was conducted in the Mingshazui region of Gulang county in Gansu province, located in the middle reaches of the Shiyang River and on the southern edge of the Tengger Desert $\left(37^{\circ} 32^{\prime}-43^{\circ} 33^{\prime} \mathrm{N}\right.$, $\left.103^{\circ} 39^{\prime}-103^{\circ} 42^{\prime} \mathrm{E}\right)$, with an elevation ranging from $1,730 \mathrm{~m}$ to $1,810 \mathrm{~m}$ (Fig. 1). The study area is a typical ecotone between the steppe and sandy deserts. It has a dry, continental climate with a mean annual temperature of $6.0^{\circ} \mathrm{C}$, a maximum temperature of $36.6^{\circ} \mathrm{C}$ and a minimum temperature of $-27.3^{\circ} \mathrm{C}$. The average sunshine per year is 2,726 hours, and the growing season is 192 days. The mean annual precipitation is $175 \mathrm{~mm}$, with most occurring from July to September; while the annual potential evaporation is about 3,080 $\mathrm{mm}$. The ground water table is $67 \mathrm{~m}$, and can not support large areas of natural vegetation. Hence, natural precipitation is usually the only source of water for plant growth. The study area is the largest shifting sandy land in the county, with a total area of $4,800 \mathrm{hm}^{2}$, with mobile sand dunes approaching the oasis at a speed of 3-5 m/a. The landscape is characterized by shifting, semi-stable, and stable sand dunes, dry riverbeds, and wind-eroded sandy land. The main soil type is sandy soil and the zonal vegetation is dominated by steppe desert, mainly consisting of Aster othamnus centraliasiaticus, Nitraria tangutorum, Artemisia ordosica, A. sphaerocephala, Psammochloa villosa and Agriophyllum squarrosum. Since 1982, afforestation with a low density (species: Hedysarum scoparium; density: 1,650 plants/ $\mathrm{hm}^{2}$ ) and enclosure has been employed to improve the sandy land. As a result, vegetation consisting of semi-shrub and perennial herb species has come into existence on the sandy land after 25 years of natural restoration (Wang et al., 2004; Wang et al., 2006).

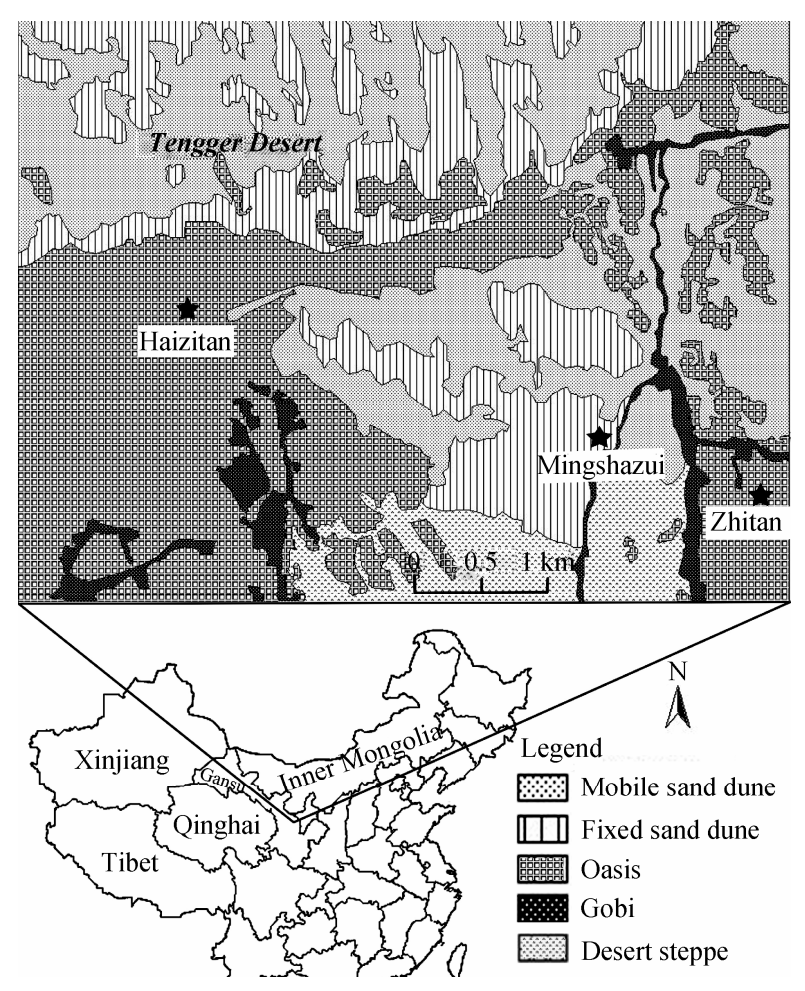

Fig. 1 Desertified lands of the study area

\section{Methods}

\subsection{Site selection}

In mid-August 2007, in the vegetation restoration region of the Mingshazui region on the southern edge of the Tengger Desert, using a method of substituting time with space, mobile sand dunes and desertified lands enclosed for 5, 15 and 25 years, respectively were selected for restoration in a series of stages in the reversion process of desertification. In order to eliminate the topography effect, all sampling plots were selected on a gentle slope of $3-6^{\circ}$, facing south.

In the reversion process of desertification on the southern edge of the Tengger Desert, the sand-binding vegetation has undergone a series of evolution from annual herb to semi-shrub, then to semi-shrub and perennial herbaceous community. The dominant species has changed from annual to perennial herbages and semi-shrubs. The above ground biomass and total 
vegetation coverage initially showed an increasing trend, then decreasing, while herb vegetation cover presented a continuous increasing trend (Table 1). After 25 years of vegetation restoration, the desertified area started to reverse.

\subsection{Soil sampling and soil water measurement}

Three typical sampling points were selected in $50 \mathrm{~m}$ intervals in each restoration stage plot. On fine days, after one week of rain, the samples were taken manually at each point from the depths of 0 to $300 \mathrm{~cm}$, in 20 cm depth increments.

Meanwhile, a larger quadrat of $20 \mathrm{~m} \times 20 \mathrm{~m}$ was established in each restoration stage plot, which was divided into 200 sub-quadrats using an adjacency grid. Fifty sub-quadrats were selected at distances from $2 \mathrm{~m}$ to $25 \mathrm{~m}$. On fine days, after one week of rain, samples were taken manually from each sub-quadrat in the depths of 0 to $60 \mathrm{~cm}$ and $20 \mathrm{~cm}$ depth increments.

Soil water contents of all soil samples were measured using an oven-dry method in the laboratory at $105^{\circ} \mathrm{C}$ for $24 \mathrm{~h}$.

\subsection{Statistical analysis and plotting}

The data was analyzed using geostatistical software, $\mathrm{GS}^{+}$(version 5, Gamma Design Software, Michigan, USA), Origin 7.5 software was used to plot, and a variogram was used to analyze the spatial heterogeneity of soil water content. The calculation formula is as follows:

$$
\gamma(h)=[1 / 2 N(h)] \sum\left[Z_{j}-Z_{j+h}\right]^{2} .
$$

Where, $\gamma(h)$ is the semivariance of all the points for $h$ spacing in the sampling range; $N(h)$ is the number of pairs of points separated by the distance $h ; Z_{j}$ is the variable value at location $j$; and $Z_{j+h}$ is the variable value at lag $h$ from $j$.
Theoretical models of the variograms were established using curve diagrams drawn from the soil water content variograms. The degree, composition and pattern of the spatial heterogeneity of soil water content were quantitatively analyzed using the main parameters of the variogram model, such as Nugget $\left(\mathrm{C}_{0}\right)$, Sill $\left(\mathrm{C}_{0}+\mathrm{C}\right)$, Range $\left(\mathrm{A}_{0}\right)$, Fractal dimension $(\mathrm{D})$ and structural variance ratio $\mathrm{C} /\left(\mathrm{C}_{0}+\mathrm{C}\right)$ (Wang, 1999).

The collected data was processed using DPS 3.01 statistical software. Duncan's test at $P<0.05$ was used to test the significance in the difference of the soil water contents among different restoration stages and different soil layers in the reversion process of desertification.

\section{Results and discussion}

\subsection{Dynamics of soil water}

Figure 2 shows the changes of soil water content in soil layers with depths of $0-300 \mathrm{~cm}$ in the reversion process of desertification on the southern edge of the Tengger Desert. At the initial restoration stage of MS, the soil water content reached $2.625 \%$ which was suitable for sand-binding plant growth. The soil water content of $5 \mathrm{a}$ reduced to $1.724 \%$, and that of $15 \mathrm{a}$ decreased to $1.22 \%$, which caused large shrubs, such as H. scoparium, and C. Korshinskii to seriously degenerate. But the soil water content of 25 a restored to $1.707 \%$, as well as the soil water content in deeper layers (below $150 \mathrm{~cm}$ ), which showed obvious restoration, exceeded that of 5a, causing shrubs $H$. scoparium and C. Korshinskii to disappear from the sand-binding vegetation system completely. Consequently, a relatively stable sand-binding vegetation system formed,

Table 1 Sand-binding vegetation changes in the reversion process of desertification

\begin{tabular}{|c|c|c|c|c|c|}
\hline Restoration stage & Species richness & Dominant species & $\begin{array}{c}\text { Vegetation coverage } \\
(\%)\end{array}$ & $\begin{array}{c}\text { Herbaceous vegetation } \\
\text { coverage }(\%)\end{array}$ & $\begin{array}{c}\text { Above-ground } \\
\text { biomass }\left(\mathrm{kg} / 100 \mathrm{~m}^{2}\right)\end{array}$ \\
\hline Mobile sand dune (MS) & 3 & A. squarrosum & 6.14 & 1.26 & 0.92 \\
\hline $\begin{array}{l}\text { Desertified land enclosed } \\
\text { for } 5 \text { years }(5 a)\end{array}$ & 5 & $\begin{array}{l}\text { H. scoparium, A.ordosica, } \\
\text { A. sphaerocephala }\end{array}$ & 18.11 & 5.22 & 20.95 \\
\hline $\begin{array}{l}\text { Desertified land enclosed } \\
\text { for } 15 \text { years }(15 a)\end{array}$ & 8 & A. ordosica & 40.23 & 8.02 & 37.90 \\
\hline $\begin{array}{l}\text { Desertified land enclosed } \\
\text { for } 25 \text { years }(25 a)\end{array}$ & 11 & A. ordosica, perennial herb & 36.44 & 8.96 & 23.05 \\
\hline
\end{tabular}


Table 2 Statistics characteristic of soil water contents in different soil layers in the reversion process of desertification

\begin{tabular}{|c|c|c|c|c|c|c|c|c|c|}
\hline Soil depth $(\mathrm{cm})$ & Stage & Mean $(\%)$ & S.D. & C.V. & Minimum value & Maximum value & Skewness & Kurtosis & Distribution pattern \\
\hline \multirow{4}{*}{$0-20$} & MS & $1.769 \mathrm{~cd}$ & 0.367 & 0.207 & 0.700 & 2.45 & -0.68 & 0.40 & $\mathrm{~N}$ \\
\hline & $5 \mathrm{a}$ & $1.518 \mathrm{e}$ & 0.377 & 0.248 & 0.54 & 2.28 & -0.40 & -0.32 & $\mathrm{~N}$ \\
\hline & $15 \mathrm{a}$ & $1.054 \mathrm{f}$ & 0.355 & 0.337 & 0.37 & 2.04 & 0.48 & -0.23 & $\mathrm{~N}$ \\
\hline & $25 \mathrm{a}$ & $1.211 \mathrm{f}$ & 0.235 & 0.194 & 0.9 & 1.89 & 1.14 & 1.12 & $\log N$ \\
\hline \multirow{4}{*}{$20-40$} & MS & $3.011 \mathrm{a}$ & 0.708 & 0.235 & 1.1 & 4.44 & -0.34 & -0.08 & $\mathrm{~N}$ \\
\hline & $5 \mathrm{a}$ & $2.111 b$ & 0.698 & 0.331 & 0.9 & 4.11 & 0.43 & -0.19 & $\mathrm{~N}$ \\
\hline & $15 \mathrm{a}$ & $1.479 \mathrm{e}$ & 0.487 & 0.329 & 0.76 & 2.65 & 0.25 & -0.93 & $\mathrm{~N}$ \\
\hline & $25 \mathrm{a}$ & $1.539 \mathrm{e}$ & 0.280 & 0.182 & 1.16 & 2.13 & 0.55 & -0.75 & $\mathrm{~N}$ \\
\hline \multirow[t]{4}{*}{$40-60$} & MS & $2.967 \mathrm{a}$ & 0.772 & 0.260 & 1.3 & 4.71 & 0.16 & -0.44 & $\mathrm{~N}$ \\
\hline & $5 \mathrm{a}$ & $1.872 \mathrm{c}$ & 0.535 & 0.286 & 1.05 & 3.19 & 0.43 & -0.47 & $\mathrm{~N}$ \\
\hline & $15 \mathrm{a}$ & $1.425 \mathrm{e}$ & 0.475 & 0.333 & 0.67 & 2.69 & 0.61 & 0.20 & $\mathrm{~N}$ \\
\hline & $25 \mathrm{a}$ & $1.592 \mathrm{de}$ & 0.349 & 0.219 & 1.03 & 2.58 & 0.80 & 0.63 & $\mathrm{~N}$ \\
\hline
\end{tabular}

Note: Mean values with different lowercase letters (a, b, c, d, e and f) are significant differences at $P<0.05$. $\mathrm{N}$ is normal distribution, LogN is log-normal distribution.

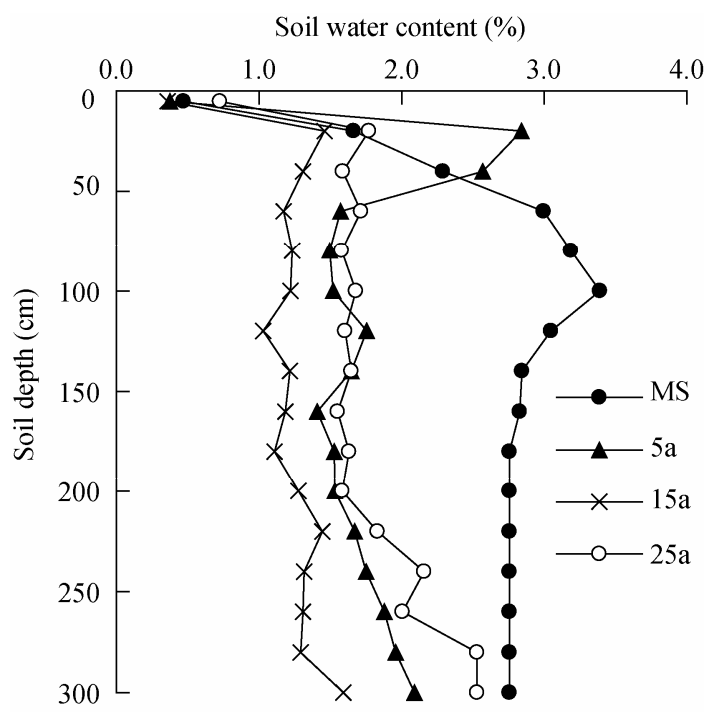

Fig. 2 The spatial variances of soil water content in the reversion process of desertification

with shallow-rooted $A$. ordosica being a constructive species. Soil water content in $0-300 \mathrm{~cm}$ layers initially showed a decreasing trend, then increased.

Table 2 shows the changes of the soil water content in 0-60 cm layers in the reversion process of desertification. The mean soil water contents in the $0-20 \mathrm{~cm}$, $20-40 \mathrm{~cm}, 40-60 \mathrm{~cm}$ and $0-60 \mathrm{~cm}$ layers of MS were all the highest among different restoration stages, followed by those of $5 \mathrm{a}$, while those of $15 \mathrm{a}$ had the lowest mean, and those of $25 \mathrm{a}$ showed a slight restoration, which was consistent with changes in the $0-300 \mathrm{~cm}$ layers. At different restoration stages, soil water content in the $0-20 \mathrm{~cm}$ layer was the lowest, which showed a significant difference in comparison to the $20-40 \mathrm{~cm}$ and $40-60 \mathrm{~cm}$ layers, respectively. The soil water contents in the $20-40 \mathrm{~cm}$ and $40-60 \mathrm{~cm}$ layers were similar. Because of strong evaporation, there is often a dry sand layer in the topsoil that reduces moisture losses from the $20-40 \mathrm{~cm}$ layer, while creating a horizon where scarce rainfall can easily penetrate, and as a result, always hold higher water content (Liu et al., 2006; Zhao et al., 2006).

Meanwhile, in the reversion process of desertification, the soil water content in different soil layers at different restoration stages presented a normal distribution except that in the $0-20 \mathrm{~cm}$ layer of $25 \mathrm{a}$. According to the coefficient of variation, the spatial variability of the soil water contents in different soil layers first increased, then decreased in the reversion process of desertification, with that of $15 \mathrm{a}$ being the highest. The distribution of the soil water contents of MS and 25a was relatively uniform, while the large spatial variability of the soil water contents of $5 \mathrm{a}$ and $15 \mathrm{a}$ may be related to the plants' thicketing effect (Table 2).

\subsection{Spatial structure characteristics of soil water}

Classical statistical methods can only describe soil properties quantitatively, and can not characterize the randomness and structure, or independence and correlation of soil properties (Li et al., 2000). The geostatistical method eliminated the limits of the classical statistical method, and can be used to analyze the spatial variation structure of soil properties (Wang, 1999). The spatial heterogeneity analysis of soil water content by the geostatistical variogram showed that the spatial variability of the soil water content in different layers fit well with the exponential and spherical models (with the large coefficient of determination $\mathrm{R}^{2}$ and 
small residual RSS), which meant the spatial distribution of soil water in the reversion process of desertification had an obvious spatial structure (Table 3, Fig. 3).

The structural variance ratio, $\mathrm{C} /\left(\mathrm{C}_{0}+\mathrm{C}\right)$ can be used to measure the degree of spatial autocorrelation. When $\mathrm{C} /\left(\mathrm{C}_{0}+\mathrm{C}\right)$ is less than $25 \%$, the spatial autocorrelation is weak. When $\mathrm{C} /\left(\mathrm{C}_{0}+\mathrm{C}\right)$ is less than $75 \%$ but more than $25 \%$, the spatial autocorrelation is moderate. When $\mathrm{C} /\left(\mathrm{C}_{0}+\mathrm{C}\right)$ is more than $75 \%$, the spatial autocorrelation is strong (Chen et al., 2003). In the reversion process of desertification, the $\mathrm{C} /\left(\mathrm{C}_{0}+\mathrm{C}\right)$ of the soil water contents at different restoration stages var- ied from 50.2 to 91.0 ; their spatial heterogeneities of autocorrelation was more than $50 \%$, and the degrees of spatial autocorrelation was moderate or strong (Table 3). The $\mathrm{C} /\left(\mathrm{C}_{0}+\mathrm{C}\right)$ of $5 \mathrm{a}$ reached $91.0 \%$, and those of $15 \mathrm{a}$ and $25 \mathrm{a}$ each exceeded $50 \%$. The nugget, $\mathrm{C}_{0}$ of $15 \mathrm{a}$ and 25a were far higher than those of MS and 5a, meaning that the spatial heterogeneity of autocorrelation decreased in the reversion process of desertification and thus, small-scale ecological processes can not be ignored.

The fractal dimension, $\mathrm{D}$, a dimensionless parameter, indicates the size of the curvature of the variogram
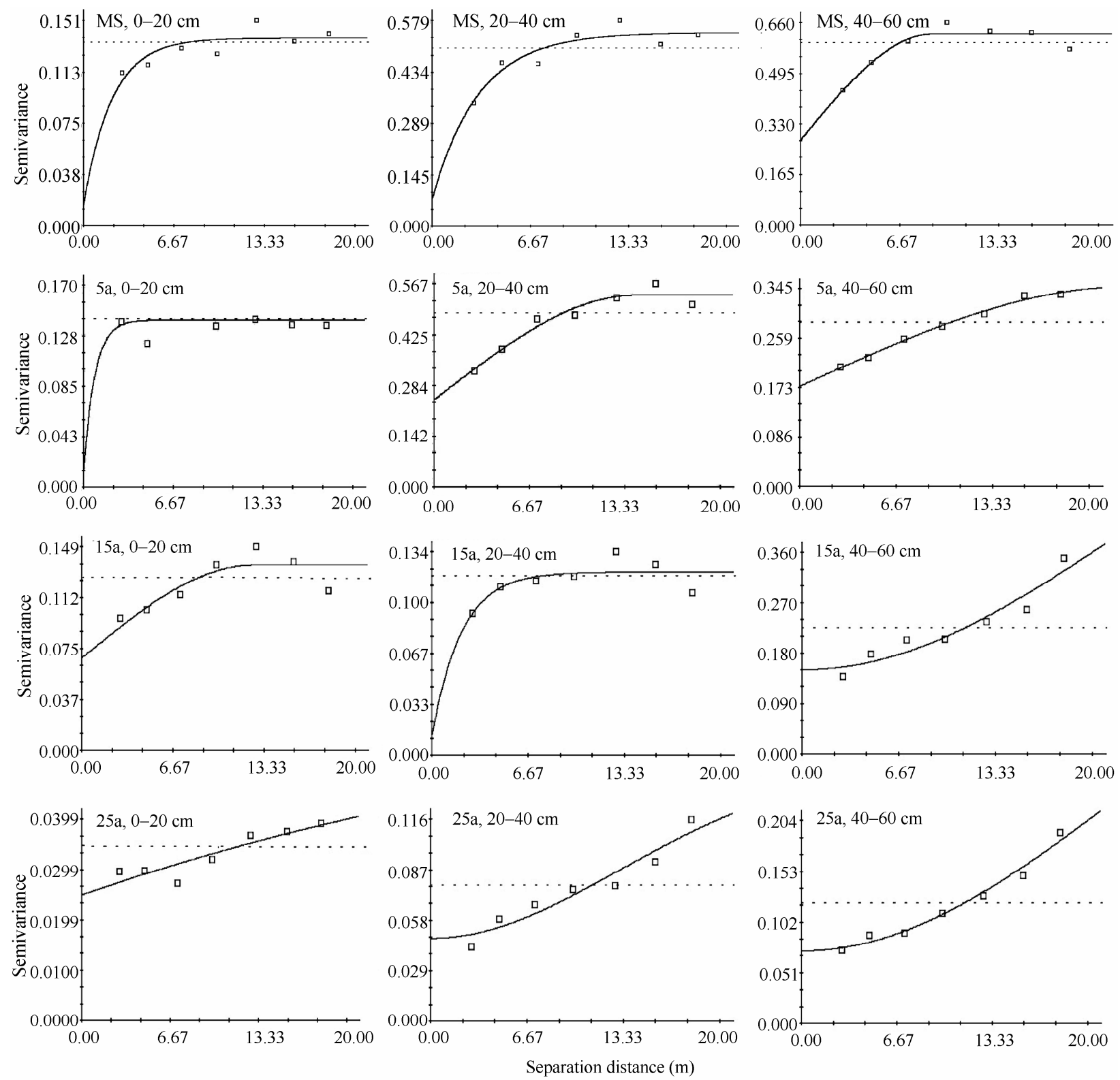

Fig. 3 Semi-variogram graphs for soil water contents in the reversion process of desertification 
Table 3 Semi-variogram model and parameters of soil water content in the reversion process of desertification

\begin{tabular}{|c|c|c|c|c|c|c|c|c|c|}
\hline Soil depth (m) & Restoration stage & Model & $\mathrm{C}_{0}$ & $\mathrm{C}_{0}+\mathrm{C}$ & $\mathrm{C} /\left(\mathrm{C}_{0}+\mathrm{C}\right)$ & $\mathrm{A}_{0}(\mathrm{~m})$ & $\mathrm{R}^{2}$ & RSS & $\mathrm{D}$ \\
\hline \multirow{4}{*}{$0-20$} & MS & Exponential & 0.0024 & 0.0208 & 0.883 & 4.51 & 0.627 & $9.773 \mathrm{E}-06$ & 1.922 \\
\hline & $5 \mathrm{a}$ & Exponential & 0.0021 & 0.0249 & 0.910 & 3.39 & 0.238 & $3.868 \mathrm{E}-05$ & 1.987 \\
\hline & $15 \mathrm{a}$ & Exponential & 0.0141 & 0.0325 & 0.568 & 16.35 & 0.857 & $1.168 \mathrm{E}-05$ & 1.892 \\
\hline & $25 \mathrm{a}$ & Exponential & 0.0174 & 0.0440 & 0.608 & 123.0 & 0.732 & $1.195 \mathrm{E}-05$ & 1.923 \\
\hline \multirow{4}{*}{$20-40$} & MS & Exponential & 0.0066 & 0.0408 & 0.838 & 11.34 & 0.969 & $5.957 \mathrm{E}-06$ & 1.855 \\
\hline & $5 \mathrm{a}$ & Exponential & 0.0160 & 0.1270 & 0.874 & 13.77 & 0.926 & $1.496 \mathrm{E}-04$ & 1.841 \\
\hline & $15 \mathrm{a}$ & Exponential & 0.0060 & 0.0418 & 0.856 & 7.20 & 0.837 & $1.671 \mathrm{E}-05$ & 1.912 \\
\hline & $25 \mathrm{a}$ & Exponential & 0.0037 & 0.0169 & 0.781 & 35.46 & 0.951 & $1.745 \mathrm{E}-06$ & 1.784 \\
\hline \multirow[t]{4}{*}{$40-60$} & MS & Spherical & 0.0208 & 0.0440 & 0.526 & 11.85 & 0.971 & $7.813 \mathrm{E}-06$ & 1.870 \\
\hline & $5 \mathrm{a}$ & Spherical & 0.0201 & 0.0458 & 0.561 & 26.40 & 0.982 & $3.521 \mathrm{E}-06$ & 1.851 \\
\hline & $15 \mathrm{a}$ & Exponential & 0.0062 & 0.0428 & 0.855 & 15.36 & 0.953 & $1.300 \mathrm{E}-05$ & 1.820 \\
\hline & $25 \mathrm{a}$ & Spherical & 0.0072 & 0.0264 & 0.726 & 31.68 & 0.973 & $2.259 \mathrm{E}-06$ & 1.795 \\
\hline
\end{tabular}

curve, and is suitable for comparison among different variables. The larger $\mathrm{D}$ is, the higher the spatial heterogeneity in the process of desertification; the $\mathrm{D}$ of soil water content in the $0-20 \mathrm{~cm}$ layer of $5 \mathrm{a}$ was the highest, followed by those of 25a and MS, while that of $15 \mathrm{a}$ was lowest, indicating the spatial heterogeneity of autocorrelation of topsoil water content of $5 \mathrm{a}$ was the highest while that of $15 \mathrm{a}$ was lowest. The total spatial heterogeneity of soil water content in the $20-40 \mathrm{~cm}$ and $40-60 \mathrm{~cm}$ layers initially increased, then decreased with those of $5 \mathrm{a}$ being the highest. All $\mathrm{C} /\left(\mathrm{C}_{0}+\mathrm{C}\right)$ values of the soil water content in the $20-40$ $\mathrm{cm}$ layer at different restoration stages approached or exceeded $80 \%$, and all those of the $40-60 \mathrm{~cm}$ layers exceeded $50 \%$. As a result, the spatial heterogeneity mainly came from spatial autocorrelation. The D of the soil water content in $20-40 \mathrm{~cm}$ layer of $15 \mathrm{a}$ was the highest, followed by $5 \mathrm{a}$ and MS, and those of $25 \mathrm{a}$ being lowest. The spatial heterogeneity of autocorrelation of $15 \mathrm{a}$ was the highest and that of $25 \mathrm{a}$ was lowest. But the D of soil water content in the 40-60 cm layer had decreased continuously; with that of 25 a being lowest, indicating that the spatial heterogeneity of autocorrelation continued to decline. The range, $\mathrm{A}_{0}$ shows the spatial autocorrelation scale of random variables, and that there is no autocorrelation between the points when the distance between them is more than $\mathrm{A}_{0}$ (Wang, 1999). The $\mathrm{A}_{0}$ values of soil water contents in different soil layers in the reversion process of desertification were obviously different, with those layers of $25 \mathrm{a}$ being the largest, indicating that the soil water content of $25 \mathrm{a}$ had spatial autocorrela- tion on an even larger scale. However, there was no significant difference in other stages. Moreover, the $\mathrm{A}_{0}$ values of soil water content in different layers at various restoration stages were larger than the sampling scale, indicating that the sampling design was reasonable.

When comparing different soil layers in the same restoration stages of the reversion process of desertification, their spatial distribution of soil water content was also significantly different. The total spatial heterogeneity of soil water content in the $0-20 \mathrm{~cm}$ layers of MS and 5a were the lowest while their spatial heterogeneity of autocorrelation was the highest. Total spatial heterogeneity of soil water content in the $0-20 \mathrm{~cm}$ layer of $15 \mathrm{a}$ was also the lowest, increasing with soil depth. However, the spatial heterogeneity of autocorrelation in the $20-40 \mathrm{~cm}$ layer was the highest, followed by the $0-20 \mathrm{~cm}$ layer, and the $40-60 \mathrm{~cm}$ layer being lowest. Total spatial heterogeneity of soil water content in the $20-40 \mathrm{~cm}$ layer of $25 \mathrm{a}$ was the lowest, followed by the $40-60 \mathrm{~cm}$ layer, and the $0-20 \mathrm{~cm}$ layer being largest, which may be related to the vegetation domination by herbs and semi-shrub A. ordosica (Table 3).

\subsection{Spatial distribution pattern of soil water content}

Estimating unobserved soil water contents using the Kriging interpolation method is another important role in establishing fitted models of the semi-variogram. The Kriging interpolation map can spatially describe the topological structures of variables, and can help to deeply understand the spatial distribution of variables (Cheng at al., 2004). The degree of spatial fragmenta- 
tion of soil water content in the $0-20 \mathrm{~cm}$ layer of $5 \mathrm{a}$ was the highest, followed by MS, and 25a being lowest, at different restoration stages in the reversion process of desertification. The degrees of spatial fragmentation of the soil water content in $20-40 \mathrm{~cm}$ and 40-60 cm layers of $5 \mathrm{a}$ and $15 \mathrm{a}$, respectively, were the highest while those of MS and 25a were low, indicating that the spatial variability of the soil water content showed an increasing trend at first, then decreased with desertification reversion at different restoration stages in the reversion process of desertification. Furthermore, the degree of spatial fragmentation of soil water in the $0-20 \mathrm{~cm}$ layer was the highest, followed by the $0-40 \mathrm{~cm}$ layer, and the $40-60 \mathrm{~cm}$ layer being the lowest, reflecting that the spatial variability of soil water content showed a decreasing trend with soil depth at different restoration stages in the reversion process of desertification (Fig. 4).

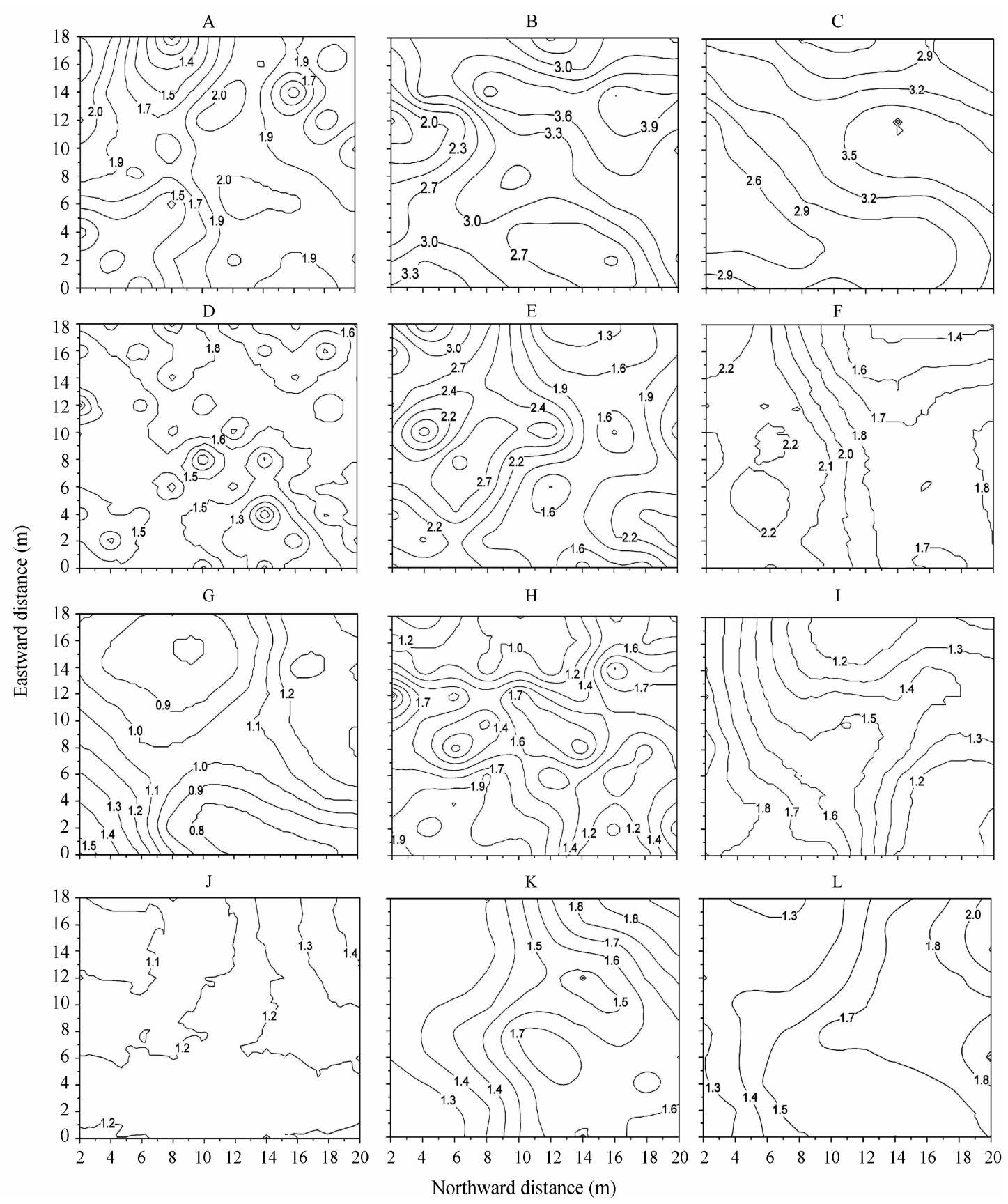

Fig. 4 Kriging interpolation maps of soil water contents in different soil layers in the reversion process of desertification A. MS, 0-20 cm; B. MS, 20-40 cm; C. MS, 40-60 cm; D. 5a, 0-20 cm; E. 5a, 20-40 cm; F. 5a, 40-60 cm; G. 15a, 0-20 cm; H. 15a, 20-40 cm; I. $15 \mathrm{a}, 40-60 \mathrm{~cm}$; J. 25a, 0-20 cm; K. 25a, 20-40 cm; L. 25a, 40-60 cm 


\section{Discussion}

The vulnerability and instability of the desert ecosystem implies that soil water is a critical ecological factor and has either a direct or indirect relationship with most of the properties and processes of the system (Huang et al., 2000). Soil water determines the emergence, development and productivity of sand-binding vegetation and the ecosystem, as a whole. It is also a key factor used in determining the stability, structure and formal functioning of ecosystems, and plays a crucial role in the water and heat balance of the entire ecosystem in desertified areas (Andrew and Robert, 2002). Therefore, soil water in arid areas has always been a focus, and a difficult one, due to a limited means of measurement. After the geostatistics method was introduced to the study of ecology, it has been used to study soil water content in arid and semiarid areas. Zhao (2002) and Li et al. (2004) reported that the establishment of artificial vegetation enhanced the heterogeneity of soil water content in a semiarid area of the Horqin sandy land. Ma et al. (2006) studied soil water content of sand-binding vegetation at the Shapotou region established in 1956, and reported that soil water content in the $0-200 \mathrm{~cm}$ layer had significant spatial variability, and the spatial heterogeneity of autocorrelation of the soil water content in different soil layers accounted for a higher degree of total spatial heterogeneity. Li et al. (2004) found that the spatial heterogeneity of soil water content in the $0-40 \mathrm{~cm}$ and $40-300 \mathrm{~cm}$ layers in the Shapotou region were enhanced for the establishment of sand-binding vegetation, but it was gradually weakened with a 50 -year vegetation evolution. In the Mingshazui region of Gulang county, located on the southern edge of the Tengger Desert, even though the spatial heterogeneity scale of soil water content in the reversion process of desertification was different from the studies in the regions mentioned above, these conclusions were similar. Moreover, by selecting different reversion process stages of desertification, it was discovered that the construction of artificial vegetation initially enhanced the spatial heterogeneity of the soil water content, which showed a decreasing trend after 25 years of restoration. The largest spatial heterogeneity of autocorrelation in the $0-20 \mathrm{~cm}$ layer occurred on the desertified land that was enclosed for 5 years, and in the $20-40 \mathrm{~cm}$ layer, on the desertified land enclosed for 15 years, which may relate to the early construction of low-density shrub vegetation (H. scoparium, $1,650 / \mathrm{hm}^{2}$ ).

The H. scoparium biomass reached full growth on the desertified land enclosed for 5 years, exhibiting an obvious thicketing effect. $H$. scoparium began to degenerate 10 years later and the thicketing effect was constantly weakening, and, as a result, the natural vegetation became dominant. In addition, compared to the study areas as mentioned above, this study area lies in the westernmost region with less precipitation (annual average $175 \mathrm{~mm}$ ), as well as scarce soil moisture. Sand-binding vegetation construction employed a low-density plantation without, in the early stages, any mechanical sand barriers. The vegetation restoration was mainly driven by natural force. Relatively uniform vegetation, dominated by semi-shrubs and herbs, formed in the study area after 25 years of enclosure, while the spatial heterogeneity of soil water was also weakening. In contrast, the artificial sand-binding vegetation in the Shapotou region was established with a high shrub density on relatively homogeneous mobile sand dunes, fixed by straw sand barriers, so the reduction of spatial heterogeneity of soil water lasted a relatively long time (Li, 2005; Ma et al., 2006).

Soil water content of sandy land is closely related to the topography, precipitation, evaporation, soil properties, and type and composition of sand-binding vegetation, and always remains fluctuating (Li et al., 2004; Li et al., 2005; Zhao et al., 2006; Shi et al., 2007; Chen et al., 2009). In the reversion process of desertification in arid areas, the sand-binding vegetation coverage on the plots with a similar landform increased from $6.14 \%$ on the mobile sand dunes to $18.11 \%$ on the desertified land enclosed for 5 years, to $40.23 \%$ on the desertified land enclosed for 15 years and finally down to $36.44 \%$ on the desertified land enclosed for 25 years. The above-ground biomass increased from $0.92 \mathrm{~kg} / 100 \mathrm{~m}^{2}$ on the mobile sand dunes to $20.95 \mathrm{~kg} / 100 \mathrm{~m}^{2}$ on the desertified land enclosed for 5 years, to $37.90 \mathrm{~kg} / 100 \mathrm{~m}^{2}$ on the desertified land enclosed for 15 years, and eventually down to 23.05 $\mathrm{kg} / 100 \mathrm{~m}^{2}$ on the desertified land enclosed for 25 years. In the reversion process of desertification, the herb coverage increased continually, and changes of vegetation coverage and its above-ground biomass 
were consistent with the soil water content and its spatial heterogeneity. Obviously, the vegetation expansion in the reversion process of desertification reduced soil water content and changed the spatial and temporal distribution of soil water content on the mobile sand dunes, resulting in a change of the vegetation pattern. The reduction of the total amount of soil water led to a decrease in the vegetation coverage and also an increase in the vegetation evenness. The shallow distribution of the soil water content caused an increase in the herbaceous species, changing the sand-binding vegetation from shrubs to herb-dominated communities. These results are consistent with the studies in adjacent areas (Liu et al., 2008).

The soil water content of sandy lands, especially in the topsoil of $0-20 \mathrm{~cm}$, is acutely changing with fluctuations in precipitation and evaporation (Liu et al., 2006). In order to better reflect characteristics of vegetation, soil and other environmental factors at different restoration stages in the reversion process of desertification, the soil water content was measured in mid-August, when the vegetation reaches its peak growing season, and grows stably. However, to further reveal the heterogeneity changes in soil water content, and its relationships with sand-binding vegetation and soil systems, studies with long-term, site-specific observation, in different scales, need to be implemented.

\section{Conclusions}

In the reversion process of desertification in arid areas, the differences in soil water content in different soil layers at different restoration stages were significant. The soil water content on the mobile sand dunes in the initial stage was the highest in the reversion process of desertification, and soil water contents in the $0-20 \mathrm{~cm}$, $20-40 \mathrm{~cm}$ and $40-60 \mathrm{~cm}$ layers were $1.769 \%, 3.011 \%$

\section{References}

Andrew J B, Robert L W. 2002. Ecological Hydrology (translated by Zhao W Z, Wang G X). Beijing: China Ocean Press, 55-81.

Berndtsson R, Chen H. 1994. Variability of soil water content along a transect in a desert area. Journal of Arid Environments, 27(2): $127-139$.

Berndtsson R, Nodomi K, Yasuda H, et al. 1996. Soil water and temperature patterns in an arid desert dune sand. Journal of Hydrology, 185(1-4): 221-240.

Burgess T M, Webster R. 1980. Optimal interpolation and isarithmic mapping of soil properties. I: The semi-variogram and punctual and $2.967 \%$, respectively, gradually reduced, and showed a restoration reaching $1.211 \%, 1.539 \%$ and $1.592 \%$ after 25 years of enclosure. The soil water content models of different soil layers at different stages were the exponential or spherical. The spatial distribution of soil water contents were in mosaic patches and had obvious spatial heterogeneity. The ratio of heterogeneity of autocorrelation to the gross spatial heterogeneity was more than $50 \%$. The gross spatial heterogeneity in the $0-20 \mathrm{~cm}$ layer presented an increasing trend, while those in the $20-40 \mathrm{~cm}$ and 40-60 cm layers, respectively, initially showed an increase, then decreased in the reversion process of desertification. The study revealed that vegetation restoration on the mobile sand dunes in arid areas would inevitably reduce the soil water content and increase its spatial heterogeneity. However, with further restoration of the vegetation-soil system in the reversion process of desertification, the soil water content showed the increase and its spatial heterogeneity presented a weakening after 25 years of enclosure. Consequently, the relationship between vegetation and the soil water content was starting to form a balance. This finding will help us further understand the ecological mechanism between soil water and sand-binding vegetation.

\section{Acknowledgements}

This study is supported by the National Natural Science Foundation of China (41061030), the "West Light" Talent Cultivation Program, the National Basic Research Program of China (2009CB421303) and the National Key Technologies R\&D Program of China (2006BAD26B0802 and 2007BAD46B03). The authors would like to thank Dr. YaoLin WANG for revising the manuscript.

kriging. Journal of Soil Science, 31(2): 315-331.

Chen F S, Zen D H, Chen G S, et al. 2003. Comparative analysis on spatial patterns of soil moisture under different land use types in Kerqin sandy land. Chinese Journal of Ecology, 22(6): 43-48.

Chen J J, Jiang J, Fu H F, et al. 2009. Soil moisture variation in south Gurbantunggut Desert. Arid Land Geography, 32(4): 537-543.

Cheng X F, Shi X Z, Yu D S, et al. 2004. Spatial variance and distribution of total nitrogen and organic matter of soil in Xingguo. China Journal Applied Environmental Biology, 10(1): 64-67.

Fortin M J, Draperal P, Legendre P. 1989. Spatial autocorrelation and 
sampling design in plant ecology. Vegetation, 83(1-2): 209-222.

Huang B W, Zheng D, Zhao M C, et al. 2000. Contemporary Physical Geography. Beijing: Science Press, 258-277.

Legender P, Fortin M J. 1989. Spatial pattern and ecological analysis. Vegetation, 80(2): 107-138.

Li C X, Wang Z H, Wang W L. 2000. Biological Statistics. Beijing: Science Press, 117.

Li X R, Ma F Y, Xiao H L, et al. 2004. Long-term effects of revegetation on soil water content of sand dunes in arid region of Northern China. Journal of Arid Environments, 57(1): 1-16.

Li X R. 2005. Influence of variation of soil spatial heterogeneity on vegetation restoration. Science in China: Series D, 35 (4): 361-370.

Liu X P, Zhang T H, Zhao H L, et al. 2006. Influence of dry sand bed thickness on soil moisture evaporation in mobile dune. Arid Land Geography, 29(4): 523-526.

Liu X P, Zhang T H, He Y H, et al. 2008. Water diffusivity of sandy soils of different particle sizes. Arid Land Geography, 31(2): 250-253.

Ma F Y, Li X R, Zhang J G, et al. 2006. Spatial heterogeneity of soil moisture in Shapotou sand-fixing artificial vegetation area. Chinese Journal of Applied Ecology, 17(5): 789-795.

Pan Y X, Wang X P. 2007. Spatial variation of soil moisture in revege- tated desert area. Journal of Desert Research, 27(2): 250-256.

Rossi R E, Mulla D J, Jourel A G, et al. 1991. Geostatistical tools for modeling and interpreting ecological spatial dependence. Ecological Monographs, 62(2): 277-314.

Shi S, Feng J C, Zou X Y. 2007. Effects of the fixed dune topography on soil water and plant growth. Arid Land Geography, 30(6): 846-851.

Wang J H, Ma Q L, Yang Z H, et al. 2004. Space-time pattern and driving mechanism of desertification land reversion in arid area. Journal of Desert Research, 24(6): 729-733.

Wang J H, Ma Q L, Liu H J, et al. 2006. Effect of wind-breaking and sand-fixing of vegetation in progressive succession on desertification land in arid area. Journal of Desert Research, 26(6): 903-909.

Wang Z Q. 1999. Geostatistics and its Application in Ecology. Beijing: Science Press, 150-156.

Zhao W Z. 2002. Impact of plantation on spatial heterogeneity of soil moisture in Horqin sandy land. Acta Pedologica Sinica, 39(1): 113-119.

Zhao X Y, Zuo X A, Zhao H L, et al. 2006. Spatial variability of soil moisture after rainfall in different type sands of Horqin Sand. Arid Land Geography, 29(4): 275-281.

\section{Xinjiang Institute of Ecology and Geography, Chinese Academy of Sciences, successfully manufactured its first mobile wind tunnel}

In order to carry out research on sand movement, the simulation of sand dune formation, soil erosion control, sand disaster control, and plant physiology and ecology under wind disturbance, the first mobile wind tunnel of Xinjiang Institute of Ecology and Geography, Chinese Academy of Sciences, was designed and manufactured by the Avic Aerodynamics Research Institute in May of 2011. The experimental wind tunnel can give a laboratory simulation of different environments in the field and also the underlying surfaces of different landscape types (such as farmlands, deserts, woodlands, a dry salt lake, the alluvial and flood plains, a dry delta, the semi-fixed desert dune, lands between mobile sand dunes, etc.).

The wind tunnel is composed of a mobile, environmental wind tunnel, which includes two field and laboratory purposes. The two-dimensional smoke wind tunnel, is used to simulate wind flow over sand dunes, and as a sand transport flux observation system. It is $8 \mathrm{~m}$ in length, $1.3 \mathrm{~m}$ in width, and $1 \mathrm{~m}$ in height. The measuring distance is $3.9 \mathrm{~m}$ using the traverse system and $4.1 \mathrm{~m}$ using the simple traverse system.

By using the new wind tunnel, it will be easier to research a two-phase sand flow simulation, the formation and evolution of aeolian landforms, sediment transport and aerodynamics, and will beneficially explain the evolution of surface sand movement in an oasis-desert region, as well as contribute to sand control and its sustainable management. 